\title{
BMJ Open Job satisfaction and associated factors among healthcare staff: a cross-sectional study in Guangdong Province, China
}

\author{
Yong Lu, ${ }^{1}$ Xiao-Min Hu, ${ }^{1}$ Xiao-Liang Huang, ${ }^{2}$ Xiao-Dong Zhuang, ${ }^{3}$ Pi Guo, ${ }^{1}$ \\ Li-Fen Feng, ${ }^{2}$ Wei Hu, ${ }^{2}$ Long Chen, ${ }^{2}$ Yuan-Tao Hao ${ }^{1}$
}

To cite: Lu Y, Hu X-M, Huang $X-L$, et al. Job satisfaction and associated factors among healthcare staff: a cross-sectional study in Guangdong Province, China. BMJ Open 2016;6: e011388. doi:10.1136/ bmjopen-2016-011388

- Prepublication history for this paper is available online. To view these files please visit the journal online (http://dx.doi.org/10.1136/ bmjopen-2016-011388).

Received 3 February 2016 Revised 2 June 2016 Accepted 29 June 2016

\section{CrossMark}

\author{
${ }^{1}$ Department of Medical \\ Statistics and Epidemiology, \\ Guangdong Key Laboratory \\ of Health Informatics, Health \\ Information Research Center, \\ School of Public Health, Sun \\ Yat-Sen University, \\ Guangzhou, Guangdong, \\ China \\ ${ }^{2}$ Government Affairs Service \\ Center of Health Department \\ of Guangdong Province, \\ Guangzhou, Guangdong, \\ China \\ ${ }^{3}$ Department of Cardiology, \\ The First Affiliated Hospital, \\ Sun Yat-sen University, \\ Guangzhou, Guangdong, \\ China
}

\section{Correspondence to}

Dr Xiao-Min Hu; huxiaom6@mail.sysu.edu.cn and Dr Xiao-Liang Huang; 688@838.cn

\section{ABSTRACT}

Objectives: This cross-sectional study aimed to explore job satisfaction among healthcare staff in Guangdong following the health system reforms in 2009 , and to investigate the association between job satisfaction and work stress, work-family conflict and doctor-patient relationship.

Design: Cross-sectional survey.

Setting: The Fifth National Health Service Survey was carried out in Guangdong, China.

Participants: All participants in this study were healthcare staff including physicians, nurses and public health staff from hospitals, health service centres and health clinics. A total of 6583 questionnaires were distributed and collected. After excluding the incomplete questionnaires, 5845 questionnaires were included for the analysis.

Outcome measures: Sociodemographic information and scores for evaluating job satisfaction, work stress, work-family conflict and doctor-patient relationship were obtained using the questionnaire developed by the National Health and Family Planning Commission of the People's Republic of China. To assess the significantly associated factors on job satisfaction of the healthcare staff in Guangdong, a binary logistic regression model was used.

Results: Based on the 5845 valid responses of the healthcare staff who worked in Guangdong, the mean score of overall perception of job satisfaction was 3.99 on a scale of 1-6. Among the sociodemographic variables, occupation, educational background, professional status, years of service, annual income and night shift frequency significantly influenced the level of job satisfaction. Work stress, work-family conflict and doctor-patient relationship also had significant effect on job satisfaction.

Conclusions: The overall job satisfaction exceeded slightly dissatisfied (score 3) and approached slightly satisfied (score 4). Measures to enhance job satisfaction include the reduction of workload, increase of welfare, maintaining moderate stress and balancing work-family conflict. Moreover, relevant laws should be issued to protect the healthcare staff from violent acts.

\section{BACKGROUND}

Job satisfaction is used to measure how content an employee is with the job. ${ }^{1}$ High

\section{Strengths and limitations of this study}

- This was a large study including 5845 healthcare professionals who were working in Guangdong, China.

- This study was the first investigating job satisfaction of healthcare staff in relation to work stress, work-family conflict and doctor-patient relationship since the major health system reforms in 2009.

- The questionnaire used in this study had only been used in China and it might not be suitable for other countries.

- This was a cross-sectional study, in which the causal effects of job satisfaction could not be determined.

job satisfaction can improve the enthusiasm of the staff and is beneficial to the success and progress of the organisation. It can lead to lower turnover ${ }^{2}$ and high quality service. ${ }^{3}$ Healthcare staff with low job satisfaction may suffer from medical problems themselves ${ }^{4}$ and individual employee health may influence the overall stability of the healthcare staff. $^{5}$ Dissatisfied employees are more likely to leave the organisation, and as a result, the remaining employees may engage in counterproductive activities such as low-quality service and cause damage to equipment. ${ }^{6}$

There are several factors are associated with job satisfaction. A survey conducted by Maissiat $e t a l^{7}$ indicated that job satisfaction was associated with professional accomplishment, freedom of expression and appreciation. An investigation undertaken by Atif et $a l^{B}$ revealed that age, educational background, years of service and income were significantly associated with job satisfaction among doctors. Other studies also mentioned that general outlook on the industry, gender, occupation, areas of work, urban versus rural setting, professional knowledge and sufficient number of staff significantly affect job satisfaction. ${ }^{9-13}$ Although work 
stress, ${ }^{14-16}$ work-family conflict ${ }^{17} 18$ and doctor-patient relationship ${ }^{19-22}$ have each been found to be associated with job satisfaction, there is little literature exploring the relationship of job satisfaction with these factors when taken together. In this study, we will analyse the impact of sociodemographic factors, work stress, workfamily conflict and doctor-patient relationship on job satisfaction among the healthcare staff in Guangdong Province.

In 2012, Guangdong Province in China had a population of 106.44 million and was ranked eighth in terms of the gross domestic product (GDP) per capita among the total 31 provinces/municipalities in mainland China. Guangdong also had the second highest number of medical personnel compared with any province in China. ${ }^{23}$ Previous studies carried out in different areas of Guangdong on job satisfaction of the healthcare staff have shown varied results. Huang et $a l^{24}$ indicated that the job satisfaction of grass-root core doctors who worked in the underdeveloped areas of Guangdong was not high. Risk of responsibility was the factor associated with the highest level of dissatisfaction. The development prospects, achievements, job setting, leadership, work stability, working environment and the salary system were the main influential factors on job satisfaction. A study conducted by Wei $e t a l^{25}$ revealed that gender, age, educational background, professional status, occupation and years of service were significant influential factors on doctors who worked in health clinics in towns and townships.

So far, no study has been undertaken in Guangdong Province on job satisfaction of healthcare professionals after the health system reforms started in 2009. The aim of the reforms is to provide safe, effective, convenient and affordable medical and health services through the establishment and improvement of basic healthcare systems covering urban and rural residents. Since the reforms, people have been using health resources at a higher rate, leading to increased workloads for the healthcare staff. The reforms also introduced new regulations and requirements for the healthcare staff, such as the essential drug list for primary care. These regulations are designed to improve quality of health but have led to reduced autonomy among the healthcare staff, with the staff reporting decreased job satisfaction as a result. ${ }^{26-29}$ It is necessary to investigate the job satisfaction of the healthcare staff under the new policy.

The objectives of this study were: (1) to explore the job satisfaction in Guangdong following the health system reforms in 2009 among the healthcare staff and (2) to investigate the association between job satisfaction and work stress, work-family conflict and doctor-patient relationship.

\section{METHODS}

Settings and participants

The data of this study was provided by the Fifth National Health Service Survey in Guangdong which was conducted from August to October 2013. The samples were obtained using multistage stratified cluster random sampling. In the first stage, 40 sample districts and counties were randomly selected from 21 prefecture-level cities. In the second stage, all tertiary hospitals and some of the secondary hospitals were selected and 200 towns (streets) and 400 villages (neighbourhoods) were randomly selected. All community health service centres and health clinics in these selected towns (streets) and villages (neighbourhoods) were included in the medical institutions. In the third stage, the sample group was selected from the medical institutions by simple random sampling, that is, randomly selected 20 medical staff and 10 nurses per hospital, 7 medical staff and 3 nurses per community health service centre/health clinics. Medical staff included physicians and public health staff. If the actual number of healthcare staff was insufficient, all healthcare staff members were selected.

Staff members filled out their own questionnaires. Each health bureau was responsible for organising the investigation. All participants in the study were voluntary and provided written informed consent before participating in this survey.

\section{Methods of measurements}

The questionnaire was developed by the National Health and Family Planning Commission of the People's Republic of China. This study involved the following five parts of the questionnaire: sociodemographic information, job satisfaction, work stress, work-family conflict and doctor-patient relationship.

The sociodemographic measures include gender, age, marital status, educational background, professional status, occupation, years of service, type of institution, employment status, administrative duties, department, hours worked per week, night shift frequency (per month), annual income, urban or rural, professional qualification and working in Pearl River Delta or not. Owing to the imbalance of economic development in Guangdong, the regions in the Pearl River Delta are considered more prosperous than the other regions. The professional status in Chinese medical institutions can be divided into four classes, that is, senior/deputy senior, intermediate, primary, lower than primary. ${ }^{30}$ The senior/deputy senior staff member is equivalent to the manager or the supervisor. The intermediate staff member is a team leader, whereas the primary staff member is a normal staff member. The staff member with a status lower than primary professional is a trainee.

The job satisfaction portion in the questionnaire includes eight items which evaluate satisfaction with colleagues, the work itself, promotions, remunerations, environment, facility, current job and superiors. They were adapted from the Job Descriptive Index (JDI). ${ }^{31}$ The presentation of the item was as such: 'I'm very satisfied with my colleagues'. The work stress portion includes four items: feel great pressure from work, feel a high level of tension from work, trouble falling asleep 
because of work and feel nervous because of work. These items were selected based on the report in ref. 32. Job satisfaction and work stress factors were measured using a six-point Likert scale, where 1-strongly disagree, 2disagree, 3-slightly disagree, 4-slightly agree, 5-agree and 6-strongly agree. The work-family conflict assessment includes nine items, which were evaluated using a five-point Likert scale, where 1-strongly disagree, 2disagree, 3-undecided, 4-agree and 5-strongly agree. ${ }^{33}$ Items one to three are time-based work-family conflict, items four to six are behaviour-based workfamily conflict and items seven to nine are strain based. The doctor-patient relationship has four items: degree to which patients respect physicians, degree to which society respects the career of physicians, degree of trust in services provided by physicians and recent doctorpatient relationship. All the participating healthcare professionals evaluated the doctor-patient relationship. Each measure was evaluated using a five-point Likert scale, where 1-strongly respectful/very good, 2respectful/good, 3-neutral, 4-disrespectful/bad and 5 - strongly disrespectful/very bad. The score of each item and the mean score in each dimension were used in the analysis.

In order to evaluate the construct validity of the questionnaire, exploratory factor analysis was applied to the above 25 items from job satisfaction, work stress, workfamily conflict and doctor-patient relationship. The factor loadings of items on each dimension are tabulated in table 1 . The results showed that the loading values of items to the corresponding dimensions were larger than 0.500 , so four factors were extracted and they were in accordance with the four dimensions. The results indicated that the questionnaire had good construct validity.

Moreover, the reliability of the questionnaire was measured by Cronbach's $\alpha$ coefficients, ${ }^{34}$ which are also presented in table 1 . The value of Cronbach's $\alpha$ reflects the internal consistency of the questionnaire and a value above 0.9 is generally regarded as excellent, above 0.8 is good and above 0.7 is acceptable. The Cronbach's $\alpha$ coefficients for the four dimensions ranged from 0.793 to 0.929 . The results also demonstrated a good level of reliability.

Table 1 Factor loading of items using the exploratory factor analysis and Cronbach's $\alpha$ of difference dimensions

\begin{tabular}{|c|c|c|c|c|}
\hline Items & $\begin{array}{l}\text { Job } \\
\text { satisfaction }\end{array}$ & $\begin{array}{l}\text { Work } \\
\text { stress }\end{array}$ & $\begin{array}{l}\text { Work-family } \\
\text { conflict }\end{array}$ & $\begin{array}{l}\text { Doctor-patient } \\
\text { relationship }\end{array}$ \\
\hline Colleagues & 0.590 & & & \\
\hline The work itself & 0.745 & & & \\
\hline Promotions & 0.766 & & & \\
\hline Remunerations & 0.763 & & & \\
\hline Environment & 0.769 & & & \\
\hline Facility & 0.765 & & & \\
\hline Current job & 0.846 & & & \\
\hline Superiors & 0.653 & & & \\
\hline Feel great pressure from work & & 0.846 & & \\
\hline Feel a high level of tension from work & & 0.866 & & \\
\hline Trouble falling asleep because of work & & 0.856 & & \\
\hline Feel nervous because of work & & 0.858 & & \\
\hline Work keeps me from family activities & & & 0.792 & \\
\hline $\begin{array}{l}\text { Time I devote to job keeps me from participating in } \\
\text { household activities }\end{array}$ & & & 0.832 & \\
\hline Miss family activities due to work & & & 0.840 & \\
\hline Problem-solving behaviours make no sense at home & & & 0.754 & \\
\hline $\begin{array}{l}\text { Behaviour that is effective and necessary at work would be } \\
\text { counterproductive at home }\end{array}$ & & & 0.687 & \\
\hline $\begin{array}{l}\text { Behaviours that make me effective at work do not help me } \\
\text { to be a better parent or spouse }\end{array}$ & & & 0.768 & \\
\hline Too frazzled to participate in family activities & & & 0.841 & \\
\hline Drain prevents me from contribution to family & & & 0.859 & \\
\hline $\begin{array}{l}\text { Owing to the pressures from work, I do not want to do } \\
\text { favourite things at home }\end{array}$ & & & 0.799 & \\
\hline Degree to which patients respect physicians & & & & 0.808 \\
\hline $\begin{array}{l}\text { Degree to which the society respects the career of } \\
\text { physicians }\end{array}$ & & & & 0.791 \\
\hline Degree of trust in services provided by physicians & & & & 0.779 \\
\hline Recent doctor-patient relationship & & & & 0.775 \\
\hline AVE & 54.924 & 73.369 & 63.792 & 62.174 \\
\hline Cronbach's $\alpha$ & 0.882 & 0.875 & 0.929 & 0.793 \\
\hline
\end{tabular}




\section{Statistical analysis}

The sociodemographic factors of the investigated healthcare staff were summarised using a descriptive statistical analysis method. Age was divided into three groups: 19-34 years, 35-44 years and 45 years or older. Years of service was divided into four groups: $0-4$ years, 5-9 years, $10-19$ years and 20 years or more. Hours worked per week were divided into three groups: 0-40 hours, 41-56 hours and 57 hours or more. Night shift frequency (per month) was divided into two groups: $0-4$ times and 5 times or more.

Job satisfaction of the healthcare staff was divided into two groups: satisfied and dissatisfied. The overall perception of job satisfaction for each respondent was calculated by taking the average scores of the eight items in job satisfaction. Using this mean score, individuals with a score higher than 3.5 were placed in the satisfied group (1), and the rest were placed in the dissatisfied group (0). Binary logistic regression was used to judge the factors significantly associated with the two levels of job satisfaction.

The sociodemographic information, subscales of work stress, work-family conflict and doctor-patient relationship were applied to the binary logistic regression model using the stepwise selection method. ${ }^{35}$ All the item scores were treated as continuous variables. OR and $95 \%$ CI of the variables were reported. All tests were conducted at the 0.05 level of statistical significance. SPSS V.20.0 was used for statistical data analysis in this study.

\section{RESULTS}

\section{Sociodemographic information of participants}

A total of 6583 printed questionnaires were distributed and collected. After reviewing the questionnaires, 738 $(11.2 \%)$ copies had missing values and were regarded as invalid, resulting in 5845 valid responses, an effective response rate of $88.8 \%$. The sociodemographic information of both the invalid and valid questionnaires was analysed using a $\chi^{2}$ test, and the results indicated that there was no significant difference between them. The final number of questionnaires considered was 5845 .

The sociodemographics of the participants are tabulated in table 2 with the number $(\mathrm{N})$ and the corresponding percentages. In this sample, $41.7 \%$ of the respondents were female and $58.3 \%$ were male. The largest proportion of respondents $(49.9 \%)$ was in the 19 34 age group, and the second largest proportion (33.5\%) was in the 35-44 age group. The average age of the respondents was $35.7 \pm 8.7$ years. Respondents' average years of service were $13.4 \pm 9.2$ years. Most of the respondents had received a bachelor's degree $(46.6 \%)$, followed by junior college $(30.9 \%)$. Most respondents had primary professional status $(39.0 \%)$, followed by intermediate professional status $(26.8 \%)$. The majority of respondents were physicians $(59.0 \%)$, while $31.3 \%$ were nurses and $9.7 \%$ were public health workers. Most of the respondents worked in hospitals $(60.3 \%)$, while $21.3 \%$ worked in community health service centres and the remaining
$18.4 \%$ worked in health clinics. Additionally, $61.2 \%$ of respondents worked for more than 40 hours per week.

\section{Job satisfaction of the healthcare staff}

Table 3 shows the degree of job satisfaction of all respondents. The mean and the SD of the scores of the eight items were calculated. The items with the highest levels of satisfaction were those with the highest mean scores: colleagues $(4.77 \pm 1.09)$, superiors $(4.72 \pm 1.24)$ and the work itself $(4.44 \pm 1.32)$. The healthcare staff members were most dissatisfied with remunerations $(3.10 \pm 1.49)$, environment $(3.15 \pm 1.46)$ and facility $(3.50 \pm 1.39)$.

A majority of respondents $(87.2 \%)$ reported that they were satisfied with their colleagues, while $84.9 \%$ were satisfied with their superiors and $78.0 \%$ were satisfied with the work itself. However, only $40.5 \%$ respondents were satisfied with remunerations, and only $56.2 \%$ and $51.5 \%$ primary care physicians were satisfied with their working environment and facility, respectively.

For analysis, we calculated the overall perception of job satisfaction by averaging the eight factors associated with job satisfaction. However, it is worth noting that one of the measures was satisfaction with current job (eg, 'Overall, I'm very satisfied with my current job'). Our calculation for overall perception of job satisfaction $(3.99 \pm 1.31)$ was similar to the respondents' who reported satisfaction with current job $(3.99 \pm 0.99)$.

Effect of sociodemographic factors, work stress, work-family conflict and doctor-patient relationship on job satisfaction

The data was further subjected to binary logistic regression using a stepwise selection and using high and low job satisfaction as the two explained variables; work stress, work-family conflict and doctor-patient relationship were taken as potential predictors; sociodemographic characteristics were used as controlled variables.

Table 4 shows the relationship between individual factors and job satisfaction. Occupation, educational background, professional status, years of service, annual income and night shift frequency (per month) were the sociodemographic factors that had significant impact on job satisfaction. The factors gender, age, marital status, type of institution, working in Pearl River Delta or not, employment status, having administrator duties, department, hours worked per week, urban or rural and professional qualification did not have significant influence on job satisfaction.

Nurses were 1.42 times more likely to be satisfied with their job than physicians $(\mathrm{OR}=1.42,95 \%$ CI 1.21 to 1.67 , $\mathrm{p}<0.01)$. Healthcare staff with a bachelor's or junior college degree were less likely to be satisfied with their job than those with an educational background below junior college $(\mathrm{OR}=0.75,95 \%$ CI 0.58 to $0.97, \mathrm{p}=0.03$; $\mathrm{OR}=0.76,95 \%$ CI 0.60 to $0.95, \mathrm{p}=0.02$ ). Employees with a higher professional status were less likely to be satisfied with their job than those with lower status $(\mathrm{OR}=0.57$, $95 \%$ CI 0.41 to $0.78, \mathrm{p}<0.01 ; \mathrm{OR}=0.57,95 \%$ CI 0.45 
Table 2 Sociodemographic information of participants

\begin{tabular}{|c|c|c|c|}
\hline Sociodemographic information & $\mathrm{N}(\%)$ & Sociodemographic information & N (\%) \\
\hline Gender & & Employment status & \\
\hline Female & $2437(41.7)$ & Permanent & $4084(69.9)$ \\
\hline Male & 3408 (58.3) & Temporary & $1761(30.1)$ \\
\hline Age & & Having administrator duties & \\
\hline $19-34$ & 2914 (49.9) & Yes & $1320(22.6)$ \\
\hline $35-44$ & $1957(33.5)$ & No & $4525(77.4)$ \\
\hline$\geq 45$ & $974(16.7)$ & Department & \\
\hline Marital status & & Internal medicine & $1610(27.5)$ \\
\hline Unmarried & $1282(21.9)$ & Surgery & 959 (16.4) \\
\hline Married & $4563(78.1)$ & Gynaecology and obstetrics paediatrics & $765(13.1)$ \\
\hline Educational background & & Traditional Chinese medicine & 225 (3.8) \\
\hline Doctor/master & $512(8.8)$ & Prevention and care & $599(10.2)$ \\
\hline Bachelor & $2725(46.6)$ & Other & $1687(28.9)$ \\
\hline Junior college & $18.9(30.9)$ & Hours worked per week & \\
\hline Lower than junior college & 799 (13.7) & $0-40$ & $2271(38.9)$ \\
\hline Professional status & & $41-56$ & $2452(42.0)$ \\
\hline Senior/deputy senior & $834(14.3)$ & $\geq 57$ & $1122(19.2)$ \\
\hline Intermediate & $1565(26.8)$ & Night shift frequency (per month) & \\
\hline Primary & 2277 (39.0) & $0-4$ & $2857(48.9)$ \\
\hline Lower than primary & $1169(20.0)$ & $\geq 5$ & $2988(51.1)$ \\
\hline Occupation & & Annual income (RMB) & \\
\hline Physician & $3450(59.0)$ & $10000-19999$ & $420(7.2)$ \\
\hline Nurse & $1827(31.3)$ & $20000-39999$ & 1649 (28.2) \\
\hline Public health staff & $568(9.7)$ & $40000-59999$ & $1323(22.6)$ \\
\hline Years of service & & $60000-79999$ & $916(15.7)$ \\
\hline $0-4$ & $1110(19.0)$ & $\geq 80000$ & $1537(26.3)$ \\
\hline $5-9$ & $1298(22.2)$ & Urban or rural & \\
\hline $10-19$ & 1907 (32.6) & Urban & $3502(59.9)$ \\
\hline$\geq 20$ & $1530(26.2)$ & Rural & $2343(40.1)$ \\
\hline Type of institution & & Professional qualification & \\
\hline Hospital & $3524(60.3)$ & Certified doctor & $2664(45.6)$ \\
\hline Community health service centre & $1245(21.3)$ & Licensed (assistant) doctor & $468(8.0)$ \\
\hline Health clinics & $1078(18.4)$ & Professional traditional Chinese medicine doctor & $431(7.4)$ \\
\hline Pearl River Delta or not & & Registered nurse & $1884(32.2)$ \\
\hline Yes & $3240(55.4)$ & Other & $398(6.8)$ \\
\hline No & $2605(44.6)$ & & \\
\hline
\end{tabular}

Table 3 Scores and percentages of satisfaction levels for items in job satisfaction

\begin{tabular}{lllll}
\hline Serial number & Items & $\begin{array}{l}\text { Scores } \\
\text { Mean } \pm \text { SD }\end{array}$ & Satisfied (\%) & Dissatisfied (\%) \\
\hline 1 & Colleagues & $4.77 \pm 1.09$ & 87.2 & 12.8 \\
2 & The work itself & $4.44 \pm 1.32$ & 78.0 & 22.0 \\
3 & Promotions & $3.76 \pm 1.43$ & 59.8 & 40.2 \\
4 & Remunerations & $3.10 \pm 1.49$ & 40.5 & 59.5 \\
5 & Environment & $3.15 \pm 1.46$ & 56.2 & 43.8 \\
6 & Facility & $3.50 \pm 1.39$ & 51.5 & 48.5 \\
7 & Current job & $3.99 \pm 1.31$ & 68.3 & 31.7 \\
8 & Superiors & $4.72 \pm 1.24$ & 84.9 & 15.1 \\
Overall perception & & $3.99 \pm 0.99$ & 71.6 & 28.4 \\
\hline${ }^{*}$ The overall perception of job satisfaction for each respondent was the average scores of the eight items.
\end{tabular}

to $0.73, \mathrm{p}<0.01)$. Healthcare staff who served for 10-19 years were 1.27 times more likely to be satisfied with their job than employees who had worked for 20 years or more (OR=1.27, 95\% CI 1.06 to 1.52 , $\mathrm{p}=0.01$ ). Employees with higher income were more likely to be satisfied with their job $(\mathrm{OR}=0.33,95 \%$ CI 0.25 to $0.45, \mathrm{p}<0.01 ; \mathrm{OR}=0.47,95 \%$ CI 0.38 to 0.58 , $\mathrm{p}<0.01 ; \quad \mathrm{OR}=0.63, \quad 95 \% \quad$ CI 0.52 to $0.77, \quad \mathrm{p}<0.01$; $\mathrm{OR}=0.71,95 \%$ CI 0.57 to $0.87, \mathrm{p}<0.01)$. Healthcare staff who worked on night shift more than or equal to 5 
Table 4 Binary logistic regression examining factors associated with job satisfaction

\begin{tabular}{|c|c|c|c|c|c|}
\hline & \multirow[b]{2}{*}{ B } & \multirow[b]{2}{*}{ p Value } & \multirow[b]{2}{*}{ OR } & \multicolumn{2}{|l|}{$95 \% \mathrm{Cl}$} \\
\hline & & & & Lower & Upper \\
\hline \multicolumn{6}{|l|}{ Occupation (reference: Physician) } \\
\hline Nurse & 0.35 & $<0.01$ & 1.42 & 1.21 & 1.67 \\
\hline Public health staff & 0.22 & 0.09 & 1.24 & 0.96 & 1.60 \\
\hline \multicolumn{6}{|l|}{ Educational background (reference: Lower than junior college) } \\
\hline Doctor/master & -0.06 & 0.72 & 0.94 & 0.66 & 1.34 \\
\hline Bachelor & -0.29 & 0.03 & 0.75 & 0.58 & 0.97 \\
\hline Junior college & -0.28 & 0.02 & 0.76 & 0.60 & 0.95 \\
\hline \multicolumn{6}{|l|}{ Professional status (reference: Lower than primary) } \\
\hline Senior/deputy senior & -0.56 & $<0.01$ & 0.57 & 0.41 & 0.78 \\
\hline Intermediate & -0.56 & $<0.01$ & 0.57 & 0.45 & 0.73 \\
\hline Primary & -0.18 & 0.07 & 0.84 & 0.69 & 1.02 \\
\hline \multicolumn{6}{|l|}{ Years of service (reference: $\geq 20$ ) } \\
\hline $0-4$ & 0.10 & 0.42 & 1.11 & 0.86 & 1.43 \\
\hline $5-9$ & 0.02 & 0.90 & 1.02 & 0.81 & 1.27 \\
\hline $10-19$ & 0.24 & 0.01 & 1.27 & 1.06 & 1.52 \\
\hline \multicolumn{6}{|l|}{ Annual income(RMB) (reference: $\geq 80000$ ) } \\
\hline $10000-19999$ & -1.11 & $<0.01$ & 0.33 & 0.25 & 0.45 \\
\hline $20000-39999$ & -0.75 & $<0.01$ & 0.47 & 0.38 & 0.58 \\
\hline $40000-59999$ & -0.46 & $<0.01$ & 0.63 & 0.52 & 0.77 \\
\hline $60000-79999$ & -0.35 & $<0.01$ & 0.71 & 0.57 & 0.87 \\
\hline \multicolumn{6}{|l|}{ Night shift frequency (per month) (reference: $0-4$ ) } \\
\hline$\geq 5$ & -0.20 & 0.01 & 0.82 & 0.71 & 0.94 \\
\hline \multicolumn{6}{|l|}{ Work stress } \\
\hline Feel a high level of tension from work & 0.22 & $<0.01$ & 1.25 & 1.17 & 1.34 \\
\hline Feel nervous because of work & -0.21 & $<0.01$ & 0.82 & 0.77 & 0.86 \\
\hline \multicolumn{6}{|l|}{ Work-family Conflict } \\
\hline Problem-solving behaviours make no sense at home & -0.21 & $<0.01$ & 0.81 & 0.75 & 0.87 \\
\hline Drain prevents me from contribution to family & -0.14 & $<0.01$ & 0.87 & 0.81 & 0.93 \\
\hline \multicolumn{6}{|l|}{ Doctor-patient relationship } \\
\hline Degree to which patients respect physicians & -0.25 & $<0.01$ & 0.78 & 0.71 & 0.86 \\
\hline Degree to which the society respects the career of physicians & -0.19 & $<0.01$ & 0.82 & 0.76 & 0.89 \\
\hline Degree of trust in services provided by physicians & -0.18 & $<0.01$ & 0.83 & 0.76 & 0.92 \\
\hline Recent doctor-patient relationship & -0.30 & $<0.01$ & 0.75 & 0.69 & 0.81 \\
\hline Constant & 5.80 & $<0.01$ & 329.30 & & \\
\hline
\end{tabular}

times a month were less likely to be satisfied with their job than other healthcare staff $(\mathrm{OR}=0.82,95 \%$ CI 0.71 to $0.94, \mathrm{p}=0.01$ ).

Analysis of the work stress measurement indicated that when the score of the item 'feel a high level of tension from work' was increased, healthcare staff were more likely to be satisfied with their job $(\mathrm{OR}=1.25,95 \%$ CI 1.17 to $1.34, \mathrm{p}<0.01)$. When the score of the item 'feel nervous because of work' increased, healthcare staff were less likely to be satisfied with their job $(\mathrm{OR}=0.82$, $95 \%$ CI 0.77 to $0.86, \mathrm{p}<0.01)$. In the work-family conflict dimension, when the scores of 'problem-solving behaviours make no sense at home' and 'drain prevents me from contribution to family' were increased, healthcare staff were less likely to be satisfied with their job $(\mathrm{OR}=0.81,95 \%$ CI 0.75 to $0.87, \quad \mathrm{p}<0.01 ; \quad \mathrm{OR}=0.87$, $95 \%$ CI 0.81 to $0.93, \mathrm{p}<0.01)$. Note that the item score in the doctor-patient relationship dimension was from 1-strongly respectful/very good to 5-strongly disrespectful/very bad. In the doctor-patient relationship dimension, when the scores of 'degree to which patients respect physicians', 'degree to which the society respects the career of physicians', 'the degree of trust in services provided by physicians' and 'recent doctor-patient relationship' decreased, healthcare staff were more likely to be satisfied with their job $(\mathrm{OR}=0.78,95 \%$ CI 0.71 to $0.86, \mathrm{p}<0.01 ; \mathrm{OR}=0.82,95 \%$ CI 0.76 to $0.89, \mathrm{p}<0.01$; $\mathrm{OR}=0.83,95 \%$ CI 0.76 to $0.92, \mathrm{p}<0.01 ; \mathrm{OR}=0.75,95 \%$ CI 0.69 to $0.81, \mathrm{p}<0.01$ ).

The binary logistic regression model in table 4 had goodness-of-fit under the Hosmer-Lemeshow test $\left(\chi^{2}=6.11, \mathrm{p}=0.64\right)$. The sociodemographic factors, work stress, work-family conflict and doctor-patient relationship were taken into the binary logistic model one by one. The values of the Cox-Snell $\mathrm{R}^{2}$ and Nagelkerke $\mathrm{R}^{2}$ of each step are shown in table 5 . The results revealed that when considering more dimensions, the ability to explain the variance of job satisfaction was higher. Based on the values of Nagelkerke $R^{2}$, the sociodemographic factors, work stress, work-family conflict and doctorpatient relationship could explain $5.8 \%, 5.1 \%, 4.4 \%$ and $6.6 \%$ variance in job satisfaction, respectively. 
Table 5 Cox-Snell $R^{2}$ and Nagelkerke $R^{2}$ of each step

\begin{tabular}{lllll}
\hline & Step 1 & Step 2 & Step 3 & Step 4 \\
\hline Cox-Snell $^{2}$ & 0.040 & 0.076 & 0.106 & 0.152 \\
Nagelkerke $R^{2}$ & 0.058 & 0.109 & 0.153 & 0.219 \\
$\Delta$ Nagelkerke $R^{2}$ & - & 0.051 & 0.044 & 0.066 \\
\hline
\end{tabular}

\section{DISCUSSION}

\section{Job satisfaction}

The mean score of overall perception of job satisfaction of healthcare staff who worked in Guangdong was 3.99 on a one to six scale. The overall perception of job satisfaction exceeded slightly dissatisfied (score 3) and approached slightly satisfied (score 4).

The item associated with the highest levels of dissatisfaction was remuneration. The importance of remuneration has also been discussed in other studies. ${ }^{27}{ }^{28}$ A study conducted at three teaching hospitals in Karachi showed that most doctors were not satisfied with their work and the lowest satisfaction was reported for wages and benefits. ${ }^{27}$ The health system reforms in China in 2009 had an unintended impact on the income of healthcare staff. According to the investigation made by Zhou et $a l,{ }^{26}$ the introduction of the basic drug list of primary healthcare, which was designed to reduce the inappropriate use of drugs, reduced the autonomy of physicians and their income. The loss of income from the mark-up of primary care was replaced by fixed wages, and in some places in the form of a performance-based bonus, but in most cases, the resulting income was lower than it had been before the reforms. ${ }^{36}$ The monetary issue and salary have been described as the most negative aspect of the work. ${ }^{37} 38$ Our results are consistent with the findings in these studies. Healthcare professionals were most sensitive to income because it has a direct impact on their lives.

The items that recorded the highest levels of satisfaction among healthcare staff in Guangdong were colleagues and superiors. This finding was in line with other recent studies. ${ }^{11} 39$ Good relationships with colleagues and support from superiors and subordinates help to improve job satisfaction. Research on social networks also showed that social support from colleagues served as a resource that affected job satisfaction. ${ }^{4041}$

\section{Sociodemographic characteristics}

The result that nurses were more satisfied with their job than physicians was in line with other studies conducted in China. ${ }^{42}$ Physicians' work risk is generally higher than that of nurses, which may contribute to lower job satisfaction. ${ }^{43}$ Although some studies revealed that higher educational level was associated with higher level of job satisfaction, ${ }^{44}{ }^{45}$ in our study there was no clear trend between educational background and job satisfaction. Healthcare staff holding a doctorate/master's degree or with an educational background lower than junior college had higher job satisfaction than healthcare staff who held a bachelor's degree or junior college degree.
High job satisfaction among staff with the lowest academic qualifications might be related to opportunities to receive continuing education. ${ }^{14}$ Healthcare staff members with the highest educational background were more satisfied with their autonomy and promotion opportunities, including the sense of professional achievement and colleagues. Their high level of education helped them seek and gain positions with less stress. ${ }^{44}{ }^{46}$ In our study, healthcare staff members with a lower professional status were more satisfied with their job than those with a higher professional status. Similar results were obtained by Liu and Wang. ${ }^{47}$ Healthcare staff with a higher professional status must live up to many expectations including the demands for interpersonal relationships and work responsibilities. They also need to undertake teaching and scientific research tasks. This greater pressure contributes to lower job satisfaction. ${ }^{47}$ The trend between years of service and job satisfaction was not clear. In our study, satisfaction with income played a significant role on job satisfaction, which was consistent with the findings of previous studies. ${ }^{41} 4849$ Annual income showed positive and significant correlation with the overall job satisfaction. The results also revealed that more night shifts reduced job satisfaction of healthcare staff. Similar results were also found by researchers in Germany and India. ${ }^{50} 51$ Some of the factors contributing to job dissatisfaction such as occupation, educational background, professional status and years of service cannot be addressed by policy reform or interventions. However, workload reduction (eg, night shifts) and increased compensation might be effective methods for increasing the job satisfaction of healthcare staff.

\section{Work stress}

Our results are in accordance with a number of studies that job satisfaction was significantly correlated with stress from work. ${ }^{52}$ According to previous studies by Meng, ${ }^{53}$ work stress was not a single concept but could be divided into good stress and bad stress. The good stress was closely related to the job itself or the motivation of the workers. Good stress made workers feel confident, energetic and positive. On the other hand, bad stress was harmful to someone's physical and mental health. In our study, feeling a high level of tension from work was positively correlated with job satisfaction, but feeling nervous because of work had a negative impact. The healthcare staff in Guangdong regarded tension from work as good stress, but nervousness caused by work as bad stress. Therefore, in the process of healthcare staff management, good stress should be appropriately increased and kept at a certain level for enhancing working ability and pressure regulation. For bad stress, contributing factors should be identified in an effort to reduce the adverse effects of bad stress.

\section{Work-family conflict}

In accordance with prior research, ${ }^{54}{ }^{55}$ our study found that work-family conflict had a negative influence on 
job satisfaction. The relationship between work-family conflict and job satisfaction was explained in this study using role stress theory, ${ }^{56}$ which assumed a disagreement between the requirements and values of an individual's work role and family role. Pressure from this disagreement would impact organisational attitudes, especially when the work was a threat to the family role. ${ }^{57}$ For example, when a nurse thought scheduling demands or the working environment affected her time and energy to participate in family activities, he or she might develop a feeling of unhappiness, reducing job satisfaction. Therefore, we assumed that we would observe reduced job satisfaction when employees experienced work-family conflict.

\section{Doctor-patient relationship}

In our study, doctor-patient relationship had the greatest impact on healthcare staff's job satisfaction. Similar to the previous studies, ${ }^{22}$ a better doctor-patient relationship was correlated with higher job satisfaction and vice versa. In recent years, the tenuous relationship between doctors and patients in China has become a major concern in society. The most visible manifestation of tension in doctor-patient relationship is violence against healthcare staff, but it can also be seen in the disruption of medical equipment. ${ }^{58} \mathrm{~A}$ study of 12 hospitals in 2009 indicated that, of 2464 medical professionals, $50 \%$ had experienced workplace violence over the past 12 months, in which $20 \%$ had physical violence at least once. ${ }^{59}$ Unsafe working environment affects the job satisfaction of healthcare staff.

\section{Strengths and limitations}

The Fifth National Health Service Survey in Guangdong was a large study, including 5845 healthcare professionals who were working in Guangdong, China. To the best of our knowledge, this study was the first investigating job satisfaction of healthcare staff in Guangdong since the major health system reforms in 2009. Job satisfaction and its influencing factors were explored and the associations of job satisfaction between work stress, work-family conflict and doctor-patient relationship were investigated.

Our study has several limitations. First, the questionnaire used in this study has only been used in China. However, it was a scientific questionnaire which was developed in line with the national conditions of China. Our results also indicated that the questionnaire had good construct validity and reliability. Second, the results only reflected the situations in Guangdong Province, and might not adapt to other regions in China due to differing implementation of policy and health system reforms across regions. However, the results were useful for evaluating the effectiveness and influence of the reforms in Guangdong. A comparison of the survey in Guangdong with the other provinces in China should be explored in future studies. Third, as the study was a cross-sectional design, the causal effects of job satisfaction could not be determined. Further study is perhaps needed for measuring the effects.

\section{Conclusions}

Healthcare staff in Guangdong Province, China reported a mean score of 3.99 for overall perception of job satisfaction on a one to six scale. The overall job satisfaction exceeded slightly dissatisfied (score 3) and approached slightly satisfied (score 4). The greatest factors of dissatisfaction and satisfaction were remunerations and colleagues, respectively. Healthcare staffs' job satisfaction was significantly associated with work stress, work-family conflict, doctor-patient relationship and sociodemographic factors, including occupation, educational background, professional status, years of service, annual income and night shift frequency (per month). Based on the results, we recommend the following measures for enhancing job satisfaction of healthcare staff in Guangdong - a reduction of employees' workload, an increase in compensation, maintaining moderate stress and balancing workfamily conflict. Moreover, relevant laws should be issued to protect healthcare staff from violent acts.

Acknowledgements The authors are thankful to all the healthcare staff who participated in the study. They are also grateful to Andrew W Babbitt, who has proofread the manuscript.

Contributors $\mathrm{YL}$ drafted the manuscript and was involved in the interpretation of the data. X-MH, X-DZ and PG performed statistical analyses. X-LH, L-FF, WH and LC played a major role in the field survey. Y-TH made a substantial contribution to the interpretation of the data and was involved in revising the manuscript. All the authors read and approved the final manuscript.

Funding This study was supported in part by the National Natural Science Foundation of China No. 61202130, NSFC Joint Fund with Guangdong under Key Project U1201258, and the Science and Technology Program of Guangdong No. 2014B010118002.

\section{Competing interests None declared.}

Ethics approval The Health Department of Guangdong Province and the Ethics Review Committee approved the study design and the collection of the data through the questionnaire.

Provenance and peer review Not commissioned; externally peer reviewed.

Data sharing statement No additional data are available.

Open Access This is an Open Access article distributed in accordance with the Creative Commons Attribution Non Commercial (CC BY-NC 4.0) license, which permits others to distribute, remix, adapt, build upon this work noncommercially, and license their derivative works on different terms, provided the original work is properly cited and the use is non-commercial. See: http:// creativecommons.org/licenses/by-nc/4.0/

\section{REFERENCES}

1. Kraut A. Job satisfaction: application, assessment, causes, and consequences. Personnel Psychol 1998;51:513-16.

2. Ahmed I. Effects of motivational factors on employees job satisfaction: a case study of University of the Punjab, Pakistan. Int J Bus Manag 2010;5:70-80.

3. Kvist T, Voutilainen A, Mäntynen R, et al. The relationship between patients' perceptions of care quality and three factors: nursing staff job satisfaction, organizational characteristics and patient age. BMC Health Serv Res 2014;14:466-75.

4. Sundquist J, Johansson SE. High demand, low control, and impaired general health: working conditions in a sample of Swedish general practitioners. Scand J Public Health 2000;28:123-31. 
5. Fahrenkopf AM, Sectish TC, Barger LK, et al. Rates of medication errors among depressed and burnt out residents: prospective cohort study. BMJ 2008;336:488-91.

6. Samad S. The contribution of demographic variables: job characteristics and job satisfaction on turnover intentions. J Hum Resources Adult Learn 2006;2:1-12

7. Maissiat GS, Lautert L, Pai DD, et al. Work context, job satisfaction and suffering in primary health care. Revista Gaúcha De Enfermagem 2015;36:42-9.

8. Atif $\mathrm{K}, \mathrm{Khan} \mathrm{HU}$, Maqbool S. Job satisfaction among doctors, a multi-faceted subject studied at a tertiary care hospital in Lahore. Pak J Med Sci 2015;31:610-14.

9. Al Jazairy $\mathrm{YH}$, Halawany $\mathrm{HS}$, Al Hussainan $\mathrm{N}$, et al. Factors affecting job satisfaction and their correlation with educational standards among dental assistants. Ind Health 2014;52:324-33.

10. Pérez-Ciordia I, Brugos A, Guillen-Grima F, et al. Job satisfaction and improvement factors in primary care professionals. An Sist Sanit Navar 2013;36:253-62

11. Tran BX, Van Hoang M, Nguyen HD. Factors associated with job satisfaction among commune health workers: implications for human resource policies. Glob Health Action 2013;6:1-6.

12. Kvist T, Mäntynen R, Vehviläinen-Julkunen K. Does Finnish hospital staff job satisfaction vary across occupational groups? BMC Health Serv Res 2013;13:1-7.

13. Kvist T, Mäntynen R, Partanen $\mathrm{P}$, et al. The job satisfaction of Finnish nursing staff: the development of a job satisfaction scale and survey results. Nurs Res Pract 2012;2012:210509.

14. Graham KR, Davies BL, Woodend AK, et al. Impacting Canadian public health nurses' job satisfaction. Can J Public Health 2011;102:427-31.

15. Ge $\mathrm{C}, \mathrm{Fu}$ J, Chang $\mathrm{Y}$, et al. Factors associated with job satisfaction among Chinese community health workers: a cross-sectional study. BMC Public Health 2011;11:884-96.

16. Fang $P Q$, Luo ZN, Fang $Z$. What is the job satisfaction and active participation of medical staff in public hospital reform: a study in Hubei province of China. Hum Resour Health 2015;13:34-47.

17. Filomena B, Marcello R. Reducing the effects of work-family conflict on job satisfaction: the kind of commitment matters. Hum Resource Manag J 2013;23:91-108.

18. Niki G, Eleonora K, Kostas Z. Relationships among three facets of family-supportive work environments, work-family conflict and job satisfaction: a research in Greece. Int J Hum Resource Manag 2013;24:3757-71.

19. Zhang X, Sleeboom-Faulkner M. Tensions between medical professionals and patients in mainland China. Camb Q Healthc Ethics 2011;20:458

20. Zhang YM, Feng XS. Empirical study on determinants of physicians job satisfaction in urban public medical institutions. Chin Health Resources 2011;14:77-9.

21. Archibald C. Job satisfaction among neonatal nurses. Pediatr Nurs 2006;32:176-9.

22. Mo XT, Xu LZ, Luo HW, et al. Medical professional perceived doctor-patient relationship, job satisfaction and turnover intention. Chin J Clin Psychol 2015;23:141-6.

23. China Statistics Yearbook. http://www.stats.gov.cn/tjsj/ndsj/2013/ indexch.htm

24. Huang WX, Wang JY, Zhang LW. Studying the grass-roots core doctors' satisfaction on their job in underdeveloped area of Guangdong. Chin Health Serv Manag 2011;4:304-6.

25. Wei YT, Pang YS, Huang JL, et al. A survey on job satisfaction of health care staff worked in township health center of Guangdong province. Chin J Health Stat 2005;1:82-5.

26. Zhou XD, Li L, Hesketh T. Health system reform in rural China: voices of health workers and service-users. Soc Sci Med 2014;117:134-41

27. Khuwaja AK, Qureshi R, Andrades M, et al. Comparison of job satisfaction and stress among male and female doctors in teaching hospitals of Karachi. J Ayub Med Coll Abbottabad 2004;16:23-7.

28. Seraj B, Ghadimi S, Mirzaee M, et al. Job satisfaction and its influential factors in dental academic members in Tehran, Iran. Ann Med Health Sci Res 2014;4:192-8.

29. Lim KK. Impact of hospital mergers on staff job satisfaction: a quantitative study. Hum Resour Health 2014;12:70-9.

30. Li L, Hu H, Sun T, et al. Work stress, work motivation and their effects on job satisfaction in community health workers: a cross-sectional survey in China. BMJ Open 2014;4:1-9.

31. Smith PC, Kendall LM, Hulin CL. The measurement of satisfaction in work and retirement. Chicago: Rand McNally, 1969.

32. Hassard J, Cox T, Murawski S, et al. Mental health promotion in the workplace-a good practice report. Luxembourg: Publications Office of the European Union, 2013.
33. Carlson DS, Kacmar KM, Williams LJ. Construction and initial validation of a multidimensional measure of work-family conflict. $J$ Vocational Behav 2002;56:249-76.

34. Gliem RR, Gliem JA. Calculating, interpreting, and reporting Cronbach's alpha reliability coefficient for Likert-type scales. Midwest Research-to-Practice Conference in Adult, Continuing, and Community Education, 2003.

35. Fang JQ. ed. Medical statistics and computer experiments-2nd Edition. Singapore: World Scientific Publishing, 2014.

36. Guan X, Liang $\mathrm{H}$, Xue $\mathrm{Y}$, et al. An analysis of China's national essential medicines policy. J Public Health Policy 2011;32: 305-19.

37. Froeschle ML, Sinkford JC. Full-time dental faculty perceptions of satisfaction with the academic work environment. J Dent Educ 2009;73:1153-70.

38. Lamberth B, Comello RJ. Identifying elements of job satisfaction to improve retention rates in healthcare. Radiol Manage 2005;27:34-8

39. Geleto A, Atomsa GE, Dessie Y, et al. Job satisfaction and associated factors among health care providers at public health institutions in Harari region, eastern Ethiopia: a cross-sectional study. BMC Res Notes 2015;8:1-7.

40. Mrayyan MT. Nurse job satisfaction and retention: comparing public to private hospitals in Jordan. J Nurs Manag 2005;13:40-50.

41. Joyce CM, Humphreys J, Schurer S, et al. Australian doctors satisfaction with their work: results from the MABEL longitudinal survey of doctors. Med J Aust 2011;194:30-3.

42. Song YL, Xie Y. A survey on job satisfaction of doctors and nurses from a hospital in Anshan. J Chin Mod Nurs 2008;5:1749-51.

43. Ma Y, Chen SW. A survey on job satisfaction of health care staff from a hospital in Dalian. Chin Hosp Manag 2005;25:58-9.

44. Rambur B, McIntosh B, Palumbo MV, et al. Education as a determinant of career retention and job satisfaction among registered nurses. J Nurs Scholarsh 2005;2:185-92.

45. Ingersoll GL, Olsan T, Drew-Cates J, et al. Nurses' job satisfaction, organizational commitment, and career intent. J Nurs Adm 2002;32:250-63.

46. Davidson $\mathrm{H}$, Folcarelli PH, Crawford S, et al. The effects of health care reforms on job satisfaction and voluntary turnover among hospital-based nurses. Med Care 1997;35:634-45.

47. Liu WW, Wang YY. Influence factors of health care staff satisfaction in tertiary hospital in domains of individual, working characteristics and organizational environment. Chin Hosp 2010;14:47-50.

48. Okerlund VW, Jackson PB, Parsons RJ. Factors affecting recruitment of physical therapy personnel in Utah. Phys Ther 1994;74:177-84.

49. Asegid A, Belachew T, Yimam E. Factors influencing job satisfaction and anticipated turnover among nurses in Sidama zone public health facilities, South Ethiopia. Nurs Res Pract 2014;2014:909768.

50. Sehlen S, Vordermark D, Schäfer $C$, et al. Job stress and job satisfaction of physicians, radiographers, nurses and physicists working in radiotherapy: a multicenter analysis by the DEGRO Quality of Life Work Group. Radiat Oncol 2009;4:1-9.

51. Kaur S, Sharma R, Talwar R, et al. A study of job satisfaction and work environment perception among doctors in a tertiary hospital in Delhi. Indian J Med Sci 2009;63:139-44.

52. Ho C-C, Hung C-T, Liu W-W, et al. Job stress, job satisfaction and propensity to leave: moderating effect of support at work-taking one regional hospital employee as an example. Med Health $J$ 2014;3:25-36

53. Meng XB. A study of relationship among work stress, self-efficacy and work performance of managers. [MD thesis]. Zhejiang University, 2004

54. Darrat M, Amyx D, Bennett R. An investigation into the effects of work-family conflict and job satisfaction on salesperson deviance. J Pers Selling Sales Manag 2010;30:239-51.

55. Simone S, Lampis J, Lasio D, et al. Influences of work-family interface on job and life satisfaction. Appl Res Qual Life 2014:4:831-61.

56. Robert Louis K. Organizational stress: studies in role conflict and ambiguity. New York: Wiley, 1964.

57. Grandey AA, Cordeiro BL, Crouter AC. A longitudinal and multi-source test of the work-family conflict and job satisfaction relationship. J Occup Organ Psychol 2005;3:305-23.

58. Wu D, Wang Y, Lam KF, et al. Health system reforms, violence against doctors and job satisfaction in the medical profession: a cross-sectional survey in Zhejiang Province, Eastern China. BM Open 2014;4:1-10.

59. Wu S, Lin S, Chai W, et al. Workplace violence and influencing factors among medical professionals in China. Am J Ind Med 2012;55:1000-8. 